\title{
Pengaruh kepuasan pelanggan, brand image, dan kepercayaan pelanggan terhadap loyalitas pelanggan pada membercard
}

\author{
${ }^{1}$ Dwi Apriliani, ${ }^{2 *}$ Nikmah Baqiyyatus S., ${ }^{3}$ Rizka Febila, ${ }^{4}$ Vicky F. Sanjaya \\ 1,2,3,4 Fakultas Manajemen Bisnis Syariah UIN Raden Intan, Jl. Letnan Kolonel H. Endro Suratmin, Lampung \\ *e-mail korespondensi: nikmahsoleha89@gmail.com
}

\begin{tabular}{l|l}
\hline \multicolumn{1}{c}{ Keywords } & \multicolumn{1}{c}{ Abstract } \\
\hline \hline $\begin{array}{l}\text { satisfaction, brand } \\
\text { image, trust, } \\
\text { customer loyalty }\end{array}$ & $\begin{array}{l}\text { This research was conducted to determine the effect of satisfaction, brand image and } \\
\text { trust on customer loyalty at member cards. This research method uses questionnaire } \\
\text { data collection techniques with the respondent data of } 100 \text { people. The process of } \\
\text { distributing questionnaires to respondents was carried out online and publicly. This } \\
\text { type of research sampling technique used in this study is purposive sampling. } \\
\text { Meanwhile, to test the data using validity and reliability tests. In testing the validity } \\
\text { using the validity of the construction. This research was analyzed with the help of } \\
\text { the smart PLS program. The results of the analysis obtained show that the customer } \\
\text { satisfaction variable has a positive and significant effect on customer loyalty at } \\
\text { member cards. Meanwhile, brand image has a negative and insignificant effect on } \\
\text { customer loyalty to member cards and the variable customer trust also has a } \\
\text { negative and insignificant effect on customer loyalty to member cards. }\end{array}$ \\
\hline
\end{tabular}

\begin{tabular}{ll}
\hline \multicolumn{1}{c}{ Kata Kunci } & \multicolumn{1}{c}{ Abstrak } \\
\hline \hline $\begin{array}{l}\text { kepuasan, citra } \\
\text { merek, } \\
\text { kepercayaan, } \\
\text { loyalitas pelanggan }\end{array}$ & $\begin{array}{l}\text { Penelitian ini dilakukan untuk mengetahui pengaruh kepuasan, citra merek dan } \\
\text { kepercayaan terhadap loyalitas pelanggan pada kartu anggota. Metode penelitian ini } \\
\text { menggunakan teknik pengumpulan data kuisioner dengan data responden sebanyak } \\
100 \text { orang. Proses penyebaran kuesioner kepada responden dilakukan secara online } \\
\text { dan publik. Jenis teknik pengambilan sampel penelitian yang digunakan dalam } \\
\text { penelitian ini adalah purposive sampling. Sedangkan untuk menguji data } \\
\text { menggunakan uji validitas dan reliabilitas. Dalam pengujian validitas menggunakan } \\
\text { validitas konstruksi. Penelitian ini dianalisis dengan bantuan program PLS pintar. } \\
\text { Hasil analisis yang diperoleh menunjukkan bahwa variabel kepuasan pelanggan } \\
\text { berpengaruh positif dan signifikan terhadap loyalitas pelanggan pada member card. } \\
\text { Sedangkan citra merek berpengaruh negatif dan tidak signifikan terhadap loyalitas } \\
\text { nasabah kartu anggota dan variabel kepercayaan nasabah juga berpengaruh negatif } \\
\text { dan tidak signifikan terhadap loyalitas nasabah kartu anggota. }\end{array}$ \\
\hline
\end{tabular}

\section{PENDAHULUAN}

Bisnis merupakan kegiatan yang di lakukan perorangan atau badan untuk mendapatkan keuntungan di mana bisnis ini menjual barang atau jasa kepada konsumen. Kegiatan bisnis baik menual barang atau jasa semakin mengalami kemajuan baik dalam bidang kuliner, fashion, ritel dan masih banyak lagi. Dengan demikian, makin sengit pula persaingan dalam dunia bisnis. Saat ini marketing ataupun pemasaran membuat banyak perusahaan berlomba- 


\section{Entrepreneurship Bisnis Manajemen Akuntansi (E-BISMA), 1(1), 20-30 \\ Dwi Apriliani, Nikmah Baqiyyatus S., Rizka Febila, Vicky F. Sanjaya}

lomba menciptakan suatu hal yang membuat konsumen menjadi tertarik, perusahaan harus selalu memperhatikan bahwa betapa pentingnya menjaga hubungan baik dengan konsumen (Kotler dan Keller, 2015). Dan juga para pemilik bisnis di harapkan mampu melakukan inovasi agar bisnisnya bisa terus berjalan. Menjaga loyaitas pelanggan merupakan strategi yang paling utama dalam dunia marketing, semakin berkembangnya dunia pemasaran semakin banyak trobosan-trobosan baru salah satunya dengan memberikan kartu keanggotaan kepada konsumen agar konsumen menjadi loyal, keanggotaan atau (membership) merupakan kegiatan perusahaan dalam menciptakan pelanggan menjadi bagian dari anggotanya yang bergabung dalam suatu organisasi.

Adapun fakto-faktor yang membuat pelanggan ingin membuat member card adalah dengan kepuasan pelanggan, persaingan bisnis dalam perkembangan era globalisasi saat ini membuat perusahaan harus cepat berfikir keras bagaimana bersikap dan bertindak ekeftif dan efesien, terlebih menghadapi persaingan dilingkungan bisnis yang bergerak sangat cepat serta mengikuti zaman dan penuh dengan ketidakpastian. Oleh karena itu, setiap perusahaan dituntut bersaing secara kompetitif dalam hal menciptakan dan mempertahankan konsumen yang loyal (pelanggan),yaitu dengan program membercard yang memberikan keuntungan salah satunya adalah pemberian diskon atau potonganharga (Winni, 2020). Engel dalam Tjiptono (2000) mengungkapkan bahwa kepuasan pelanggan adalah evaluasi purna beli dimana alternatif yang dipilih dan minimal memberikan hasil (outcome) sama atau melampaui harapan pelanggan, sedangkan ketidakpuasan timbul apabila hasil yang diperoleh tidak memenuhi harapan pelanggan (Putra and Aziz, 2019).

Adapun hal lain strategi yang dapat digunakan agar brand dapat bersaing dalam dunia bisnis ialah dengan membangun serta menciptakan brand image yang baik di mata konsumen. Menurut Agatha \& Widiartanto (2020) Pada tingkat persaingan yang tinggi, brand memberikan imbalan dalam menciptakan dan menjaga daya saing. Untuk itu, perusahaan harus memciptakan image positif bagi brand yang dijalankannya supaya dapat menjadi market leader. Brand image yang positif mampu mendapatkan ataupun mempertahankan loyalitas konsumen. Menurut Isamani (2008, dalam Bastian, 2014), tanpa citra merek yang kuat dan positif, tidak mudqh bagi perusahaan untuk menarik pelanggan baru dan mempertahankan yang sudah ada. Hal tersebut di perkuat oleh hasil penelitian dari Brand et al. (2017) yang menyatakan bahwa Brand Image memberikan pengaruh positif dan signifikan terhadap Loyalitas Konsumen.

Kemudian strategi yang dapat dilakukan adalah dengan menambah variabel kepercayaan pelanggan. Loyalitas pelanggan akan terbangun ketika terdapat kepercayaan pelanggan, begitu juga dengan brand image yang merupakan representasi keseluruhan persepsiterhadap merek dan dibentuk dari informasi dan pengalaman masa lalu terhadap merek itu. Citra terhadap merek berhubungan dengan sikap yang berupa keyakinan dan imsge terhadap suatu merek. Konsumen yang memiliki citra yang positif terhadap suatu merek, akan lebih menjanjikan untuk melakukan pembelian. Nugroho, AW; Sudaryanto, (2013) berpendapat bahwa hubungan antara kepercayaan dengan loyalitas pelanggan yaitu, semakin tinggi kepercayaan pelanggan terhadap suatu produk barang atau jasa, maka akan semakin tinggi pula tingkat kesetiaan pelanggan pada suatu merek. Komitmen pelanggan 
terhadap produk merupakan kepercayaan dalam menggunakan suatu produk dimana meliputi rekomendasi dan kepercayaan.

Maka dari itu penulis memilih variabel kepuasan pelanggan terhadap loyalitas untuk melanjutkan penelitian dari Oliviana et al. (2017) menyarankan untuk menggunakan faktorfaktor lainnya yang memiliki keterkaitan dengan loyalitas pelanggan. Lee et al. (2014) bahwa loyalitas pemegang kartu keanggotaan dipengaruhi oleh customer satisfication, bahwa pelanggan akan loyal menjadi anggota dari sebuah program loyalitas perusahaan ketika dia merasa puas dengan layanan perusahaan tersebut. Maka penulis memilih variabel kepuasan pelanggan terhadap loyalitas pada pengguna member card untuk melanjutkan penelitian (Utami, 2019) dalam penelitiannya menyarankan untuk penelitian selanjutnya, lebih baik menambahkan variabel lain yang dapat mempengaruhi kesetiaan pelanggan atau loyalitas pelanggan, serta menambah jumlah sempel agar hasilnya lebih akurat lagi.kemudianvariabel brand image terhadap loyalitas pada pengguna member card untuk melanjutkan penelitian Rizaldi \& Hardini, (2018) bahwa terdapat saran bagi peneliti selanjutnya di harapkan untuk menambahkan brand image agar mendorong pelanggan senantiasa loyal, dan terakhir penulis memilih variabel kepercayaan pelanggan terhadap loyalitas pada pengguna member card untuk melanjutkan penelitian Idris, (2017) diharapkan peneliti selanjutnya dapat menambahkan variabel-variabel lainnya untuk mengetahui faktorfaktor yang lebih mempengaruhi customer trust dan customer loyalty. Berdasarkan gap lainnya ya itu oleh Nurhanah et al., (2019) alangkah baiknya pimpinan Toko Rabbani lebih meningkatkan kembali agar pelanggan melakukan pembuatan member card dan memberikan benefit yang cukup untuk para member card Rabbani. Oleh karena itu peneliti memilih member card sebagai objek penelitiannya yang berpengaruh terhadap loyalitas pelanggan. Tujuan dari penelitiann ini adalah untuk mengetahui pengaruh ke tiga variabel tersebut terhadap loyalitas pelanggan dengan menggunakan member card sebagai studi kasus.

\section{TEORI DAN HIPOTESIS}

\section{Kepuasan Pelanggan}

Kepuasan pelanggan terjadi apabila adanya sikap puas pelanggan atas pelayanan yang sesuai dengan yang diharapkan, dan dalam kesesuaian harga dengan pelayanannya (Idris et al., 2019). Maka hal ini menurut Maya et al., (2020) dimana kepuasan pelanggan akan meningkatkan peniliaian pelanggan atas kinerja,dengan demikian kepuasan pelanggan positif dan signifikan terhadap loyalitas pelanggan sebesar 8,383 . Hal ini sependapat dengan Hartanto \& Andreani, (2019)di temukan bahwa kepuasan pelanggan juga berpengaruh positif dan signifikan terhadap loyalitas pelanggan dimana kepuasan pelanggan akan menurun jika kinerja kurang dari harapan dan jika sesuai harapan pelanggan akan merasa puas. Choiriah \& Liana, (2019) dalam penelitiannya juga menunjukkan bahwa kepuasan pelanggan berpengaruh positif dan signifikan terhadap loyalitas pelanggan. Namun di dalam penelitianPradana, (2018) dalam hasil penelitiannya menunjukkan bahwa kepuasan pelanggan memiliki efek negatif dan tidak signifikan pada loyalitas pelanggan karena berdasarkan Berdasarkan hasil data di ketahui variable Kepuasan Pelanggan t hitung lebih 
kecil dari t tabel 0,681 < 1.66105 dengan nilai probabilitas lebih besar dari taraf signifikan 0,249>0,05 maka Kepuasan Pelanggan tidak berpengaruh dan tidak signifikan terhadap Loyalitas pelanggan, tetapi Ulfa \& Mayliza, (2019) variabel kepuasan pelanggan berpengaruh secara positif dan signifikan terhadap loyalitas pelanggan dimana kepuasan yang terdiri dari beberapa indikator diantaranya adalah perasaan yang timbul setelah mengevaluasi pengalaman setelah pemakaian produk, respon pelanggan setelah mengevaluasi, evaluasi purnabeli keseluruhan, ukuran kinerja dan tingkat perasaan hal ini dapat diketahui dari pelanggan tersebut, kemudian menurutPutra \& Aziz, (2019) dalam hasil penelitiannya menunjukkan bahwa kepuasan pelanggan berpengaruh signifikan terhadap loyalitas pelanggan, Supertini et al., (2020) juga bependapat demikian dalam hasil penelitiannya menunjukkan bahwa kepercayaan dan kepuasan pelanggan berpengaruh positif dan signifikan terhadap loyalitas pelanggan.

$\mathrm{H} 1$ : kepuasan pelanggan berpengaruh positif terhadap loyalitas pelanggan

\section{Brand Image}

Menurut Setiadi (2003) citra merek (brand image) merupakan representasi dari keseluruhan persepsi terhadap merek dan dibentuk dari informasi dan pengalaman masalalu terhadap merek itu. Brand image sebagai persepsi dan pandangan konsumen terhadap suatu merek sehingga merek tersebut melekat dalam ingatan konsumen dengan melibatkan loyalitas pelanggan yang merupakan variabel terikat dapat didefinisikan sebagai komitmen yang kuat dari pelanggan untuk berlangganan kembali atau melakukan pembelian ulang produk/jasa yang disukaisecara konsisten di masa yang akan datang. Nilai rata-rata tertinggi untuk variabel brand image ada diangka 4,63 sedangkan nilai terendah diangka 3,87. Nilai rata-rata terendah terdapat pada indikator pernyataan rasa bangga terhadap penggunaan produk,Harjati, (2020) brand image dan brand trust secara bersama-sama berpengaruh positif terhadap loyalitas pelanggan,Agatha \& Widiartanto, (2020) pada tingkat persaingan yang tinggi brand image memberikan kontribusi dalam menciptakan dan menjaga daya saing. Untuk itu perusahaan harus membentuk image positif bagi brand. Pramudyo (2012) menurut hasil penelitiannya menunjukkan bahwa mahasiswa menjadi loyal dengan adanya citra merek yang positif dari perguruan tinggi. Santana (2019) semakin tinggi brand image maka semakin kuat mempengaruhi kepuasan dan loyalitas pelangan.Salim \& Zuhdi (2018)menurut hasil penelitiannya brand image dan loyalitas pelanggan menunjukkan hubungan yang sangat kuat. Artinya semakin tinggi brand image maka semakin tinggi pula loyalitas pelanggan.Oliviana et al (2017) berpendapat bahwa brand image dan WOM memiliki pengaruh dan signifikan terhadap loyalitas pelanggan, hal ini juga sependapat dengan Dewi Yuliana, Heri Wijayanto, (2020) didalam hasil penelitiannya bahwa brand image berpengaruh positif terhadap loyalitas pelanggan karena brand image sangatlah penting karena brand image merupakan simbol pada usaha, dan sebagai pembeda antara suatu usaha dengan pesaing dan juga bisa menentukan keberhasilan dari suatu usaha dimana brand image yang baik memberikan efek positif kepada konsumen. Tetapi di dalam penelitian Handayani, (2020) didalam hasil penelitiannya variabel brand image berpengaruh negatif dan tidak signifikan terhadap loyalitas pelanggan. Prasetyo et al., (2020) secara 


\section{Entrepreneurship Bisnis Manajemen Akuntansi (E-BISMA), 1(1), 20-30 \\ Dwi Apriliani, Nikmah Baqiyyatus S., Rizka Febila, Vicky F. Sanjaya}

persial brand image berpengaruh positif dan signifikan terhadap loyalitas karena Semakin kuat Brand image di benak pelanggan maka semakin kuat pula rasa percaya diri pelanggan untuk tetap loyal atau setia terhadap produk yang dibelinya sehingga hal tersebut dapat mengantar sebuah perusahaan untuk tetap mendapatkan keuntungan dari waktu kewaktu.Novia Andarwati Sitorus, 2020)juga setuju bahwa brand image berpengaruh positif and signifikan terhadap loyaltitas pelanggan.

$\mathrm{H} 2$ : Brand image berpengaruh positif terhadap loyalitas pelanggan

\section{Kepercayaan pelanggan}

Kepercayaan pelanggan merupakan salah satu kunci yang menjadi unsur penting dalam membangun loyalitas pelanggan, kepercayaan terhadap merek terbentuk dari pengalaman masa lalu, sehingga didalam penelitianSoleh, (2018)Hasil dari penelitian nya menunjukkan bahwa kepercayaan berpengaruh signifikan terhadap loyalitas pelanggan. Wiwoho, (2018) dengan melakukan penelitianya juga di dapat hasil bahwa hasil perhitungan yang telah dilakukan pada uji t membuktikan bahwa hasil bepengaru positif dan signifikan terhadap loyalitas pelanggan di PT. Asuransi jiwasyaya cabang kota malang dan hal ini sependapat dengan penelitian (Razak, Baheri and Ramadhan, 2018) kepercayaan konsumen memiliki arti semakin tinggi kepercayaan nasabah maka loyalitas nasabah semakin tinggi. Tetapi di dalam penelitian Sukmawati, (2015) kepercayaan pelanggan berpengaruh negatif dan tidak signifikan terhadap loyalitas pelanggan, dimana ada pengaruh langsung antara variabel kepercayaan pelanggan terhadap loyalitas pelanggan tetapi tidak signifikan. Maka hipotesis di tolak dengan kontribusi sebesar 10,6\%, namun hal ini berbeda dengan penelitian (Abidin, 2018)kepercayaan konsumen dengan nilai t hitung untuk variabel trust 2,154. Dan nilai signifikannya 0,034 <0,05, sependapat dengan Dede Nurhanah, Apri Budianto, (2019) di dalam penelitiannya bahwa tingkat hubungan kepercayaan konsumen termasuk kedalam hubungan sangat kuat, artinya variabel kepercayaan berpengaruh positif dan signifikan terhadap loyalitas pelanggan. Hasil penelitian yang di lakukan penelitian sejalan dengan penelitian Idris, (2017)kepercayaan konsumen mempunyai pengaruh positif dan signifikan terhadap loyalitas pelanggan pada toko buku Gramedia Jember.

H3: Kepercayaan pelanggan berpengaruh positif terhadap loyalitas pelanggan

\section{Loyalitas Pelanggan}

Loyalitas adalah suatu komitmen yang mendalam untuk melakukan pembelian ualng atau berlangganan suatu produk (jasa) secara konsisten di masa yang akan datang yang mengakibatkan terjadinya pembelian ulang atas merek yang sama meskipun terdapat pengaruh siruasi dan usaha-usaha pemasaran yang berpotensi menyebabkan tindakan pemindahan merek (Oliver, 1999)

\section{METODE PENELITIAN}

Penelitian ini merupakan penelitian dari hasil survei kepada seluruh kalangan yang memiliki membercard. Sampel yang diambil sebanyak 100 orang responden. Survei 


\section{Entrepreneurship Bisnis Manajemen Akuntansi (E-BISMA), 1(1), 20-30}

Dwi Apriliani, Nikmah Baqiyyatus S., Rizka Febila, Vicky F. Sanjaya

dilakukan dengan menyebarkan kuisioner secara online melalui berbagai macam media sosial.

Adapun teknik sampling yang digunakan dalam penelitian ini adalah purposive sampling. Teknik purposive sampling adalah teknik penentuan dan pengambilan sampel yang ditentukan oleh peneliti dengan pertimbangan tertentu (Listiono and Sugiarto, 2015). Pada penelitian ini menggunakan dua uji data yaitu, uji validitas dan uji reliabilitas. Sedangkan untuk uji validitasnya menggunakan validitas konstruksi. Validitas konstruksi adalah sebuah gambaran yang menunjukkan sejauh mana alat ukur itu menunjukkan hasil yang sesuai dengan teori (Azwar, 2005). Penelitian ini dianalisis dengan bantuan program smart PLS. Uji validitas untuk menunjukkan nilai hasil dari beberapa indikator yang valid dengan diatas 0,6. Batas dari setiap indikator adalah faktor loading >0,6 (Hair et al., 2010). Sedangkan uji reliabilitas menunjukkan hasil yang reliable sehingga dapat dilakukan dengan pengujian hipotesis.

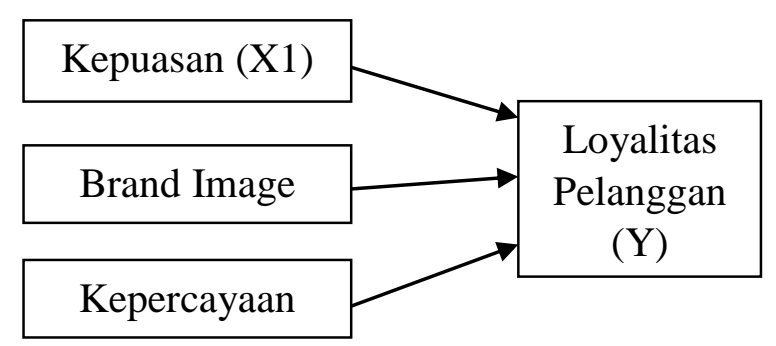

Gambar 1. Kerangka Pikir

\section{HASIL DAN PEMBAHASAN}

Hasil dari uji validitas pertama menunjukkan bahwa ada beberapa indikator yang gugur karena tidak memenuhi standar di atas 0,6. Batas dari setiap indikator adalah faktor loading $>0,6$ (Hair et al., 2010). Dilihat dari bagan bahwa pada variabel KP terdapat indikator yang factor loadingnya kurang dari 0,6 ada pada indikator KP5, untuk variabel B terdapat pada indikator B4, untuk variabel KC tidak ada indikator yang dihapus, namun pada variabel $\mathrm{L}$ terdapat satu indikator yang dihapus yakni pada L5. 


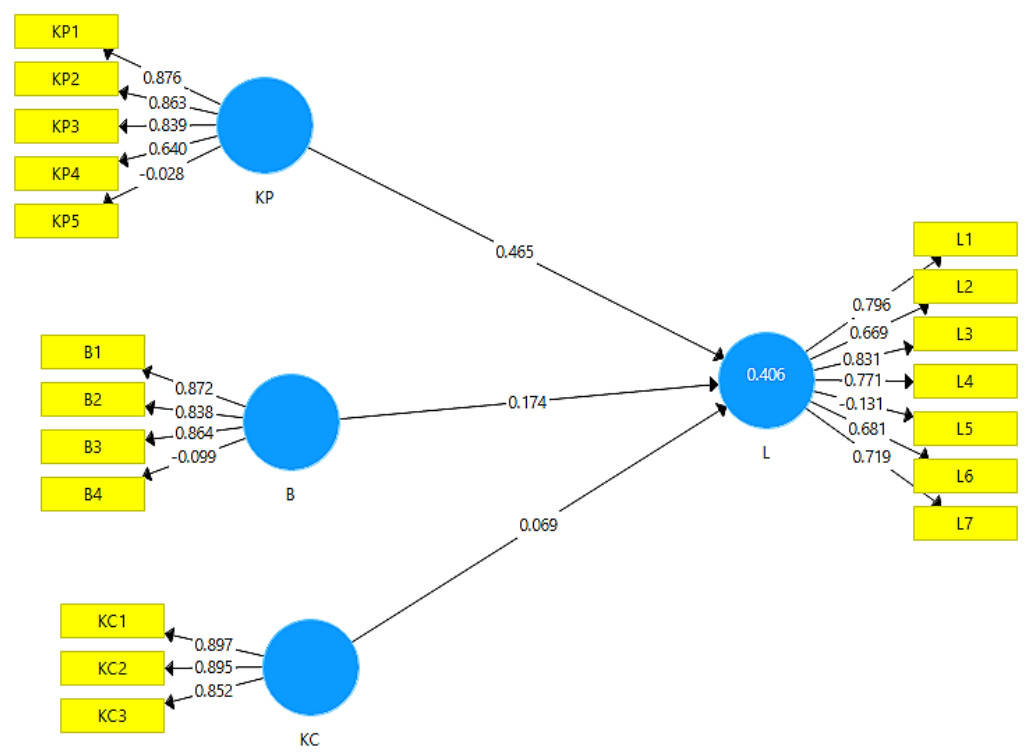

Gambar 2. Uji Validitas

Selanjutnya dilakukan pengujian ulang dengan menghapus indikator yang $<0,6$, hasil menunjukkan bahwa factor loading $>0,6$ dengan ini kami nyatakan bahawa setiap indikator dinyatakan valid.

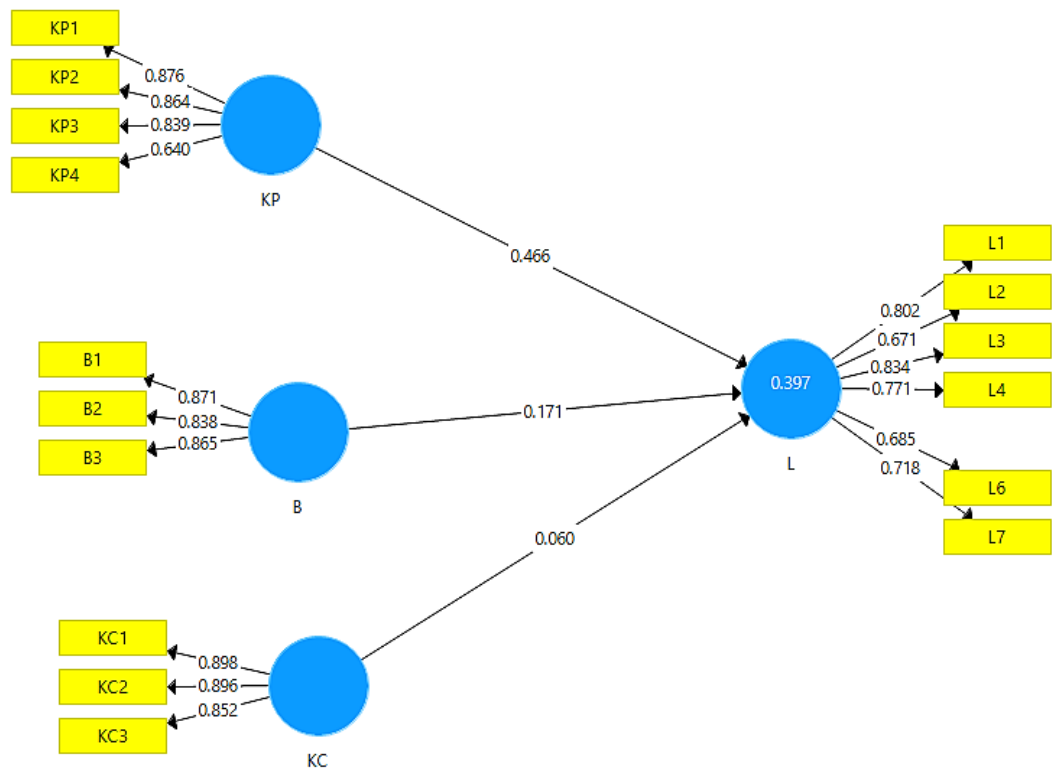

Gambar 3. Uji Reliabilitas

Setelah itu kami melakukan uji reliabilitas hasil menunjukkan bahwa setiap variabel $>0,6$ dan dapat dinyatakan reliable sehingga dapat dilakukan pengujian hipotesis. Besarnya pengaruh X1, X2 dan X3 ke variabel Y sebesar 0,397 
Entrepreneurship Bisnis Manajemen Akuntansi (E-BISMA), 1(1), 20-30

Dwi Apriliani, Nikmah Baqiyyatus S., Rizka Febila, Vicky F. Sanjaya

Tabel 1. Data Validitas Konstruksi

\begin{tabular}{|c|c|c|c|c|}
\hline Variabel & Cronbach's Alpha & rho_A & Composite Reliability & AVE \\
\hline KC & 0.857 & 0.858 & 0.913 & 0.778 \\
\hline L & 0.843 & 0.850 & 0.884 & 0.561 \\
\hline B & 0.822 & 0.832 & 0.894 & 0.737 \\
\hline KP & 0.822 & 0.849 & 0.883 & 0.657 \\
\hline
\end{tabular}

Tabel 2. Data primer dengan SmartPLS 2020

\begin{tabular}{|c|c|c|}
\hline Variabel & T Statistic & P Values \\
\hline $\mathrm{KP}$ & 3.907 & 0.000 \\
\hline $\mathrm{B}$ & 1.299 & 0.194 \\
\hline $\mathrm{KC}$ & 0.575 & 0.565 \\
\hline
\end{tabular}

\section{Penjelasan Variabel:}

KP : Kepuasan Pelanggan

$\mathrm{B}$ : Brand Image

KC : Kepercayaan Pelanggan

L : Loyalitas Pelanggan

\section{Uji Hipotesis 1}

Dari hasil yang didapatkan menunjukkan bahwa nilai signifikasi pengaruh kepuasan (X1) terhadap loyalitas (Y) pada membercard adalah $0,000<0,05$ dan nilai thitung 3,907> nilai t tabel 1,985 maka dapat disimpulkan bahwa kepuasan pelanggan berpengaruh positif dan signifikan terhadap loyalitas pelanggaan pada membercard. Hipotesis kepuasan dinyatakan diterima. Hasil tersebut mendukung penelitiannya (Ulfa and Mayliza, 2019) yang menyatakan bahwa kepuasan pelanggan berpengaruh secara positif dan signifikan terhadap loyalitas pelanggan.

\section{Uji Hipotesis 2}

Dari hasil yang didapatkan menunjukkan bahwa nilai signifikasi P-value pengaruh brand image (X2) terhadap loyalitas pelanggan (Y) pada membercard adalah 0,194>0,05 dan nilai t hitung 1,299<1,985 maka dapat disimpulkan bahwa brand image berpengaruh positif dan tidak signifikan. Dan hipotesis brand image dinyatakan ditolak.

\section{Uji Hipotesis 3}

Dari hasil yang didapatkan menunjukkan bahwa nilai signifikasi P-value pengaruk kepercayaan (X3) terhadap loyalitas pelanggan (Y) pada membercard adalah 0,565>0,05 dan nilai t hitung 0,575<1,985 maka dapat disimpulkan bahwa kepercayaan pelanggan berpengaruh negatif dan tidak signifikan terhadap loyalitas pelanggan pada membercard. Dengan begitu hipotesis kepercayaan pelanggan dinyatakan ditolak. Hasil ini didukung oleh penelitiannya Dewi, (2017) bahwa variabel kepercayaan pelanggan tidak berpengaruh positif dan signifikan terhadap loyalitas pelanggan. 


\section{Entrepreneurship Bisnis Manajemen Akuntansi (E-BISMA), 1(1), 20-30}

Dwi Apriliani, Nikmah Baqiyyatus S., Rizka Febila, Vicky F. Sanjaya

\section{KESIMPULAN DAN SARAN}

Berdasarkan uji t tabel dan uji values dapat kita lihat dari bagan 1 bahwa pada variabel KP terdapat indikator yang factor loadingnya kurang dari 0,6 ada pada indikator KP5, untuk variabel B terdapat pada indikator B4, untuk variabel $\mathrm{KC}$ tidak ada indikator yang dihapus, namun pada variabel L terdapat satu indikator yang dihapus yakni pada L5.Selanjutnya dilakukan pengujian ulang dengan menghapus indikator yang $<0,6$, hasil menunjukkan bahwa factor loading >0,6 dengan ini kami nyatakan bahawa setiap indikator dinyatakan valid.Uji Reliabilitas Setelah itu kami melakukan uji reliabilitas hasil menunjukkan bahwa setiap variabel $>0,6$ dan dapat dinyatakan reliable sehingga dapat dilakukan pengujian hipotesis.

Variabel kepuasan pelanggan dari hasil yang didapatkan menunjukkan bahwa nilai signifikasi pengaruh kepuasan (X1) terhadap loyalitas (Y) pada membercard adalah 0,000 $<0,05$ dan nilai t hitung 3,907> nilai t tabel 1,985 maka kepuasan pelanggan berpengaruh positif dan signifikan terhadap loyalitas pelanggaan pada membercard.

Variabel brand image dari hasil yang didapatkan menunjukkan bahwa nilai signifikasi $\mathrm{P}$-value pengaruh brand image (X2) terhadap loyalitas pelanggan (Y) pada membercard adalah 0,194>0,05 dan nilai t hitung 1,299<1,985 maka brand image berpengaruh positif dan tidak signifikan.

Variabelkepercayaan pelanggan dari hasil yang didapatkan menunjukkan bahwa nilai signifikasi P-value pengaruh kepercayaan (X3) terhadap loyalitas pelanggan (Y) pada membercard adalah $0,565>0,05$ dan nilai thitung $0,575<1,985$ maka kepercayaan pelanggan berpengaruh positif dan tidak signifikan terhadap loyalitas pelanggan pada membercard.

Saran bagi peneliti selanjutnya agar menambah jumlah sempel, lebih mengembangkan variabel serta lebih spesifik dalam memilih member card yang akan diteliti.

\section{DAFTAR PUSTAKA}

Abidin, Z. (2018) 'Pengaruh Brand Image Dan Trust Terhadap LoyalitasPelanggan', Jurnal Sains Manajemen dan Bisnis Indonesia, 8(2), pp. 228-243. doi: 10.32528/jsmbi.v8i2.1791.

Agatha, C. and Widiartanto (2020) 'PENGARUH BRAND IMAGE DAN BRAND LOVE TERHADAP BRAND LOYALTY ( STUDI PADA PEMILIK MEMBERSHIP CARD ORYZA GYM SEMARANG ) Administrasi Bisnis, Universitas Diponegoro, Indonesia Email: cintya.agatha06@gmail.com Abstract Abstrak Pendahuluan Latar Belakang Rum', Jurnal Ilmu Administrasi Bisnis, 9(2).

Bastian, D. A. (2014) 'Analisa Pengaruh Citra Merek (Brand Image) dan Kepercayaan Merek (Brand Trust) Terhadap Loyalitas Merek (Brand Loyalty) ADES PT. Ades Alfindo Putra Setia', Jurnal Manajemen Pemasaran Petra.

Choiriah, E. N. and Liana, L. (2019) 'Pengaruh kualitas produk, citra merek, dan kualitas layanan terhadap loyalitas pelanggan dimediasi kepuasan pelanggan pada pelanggan c', Jurnal Bereputasi.

Dede Nurhanah, Apri Budianto, T. (2019) 'PENGARUH CUSTOMER TRUST DAN CUSTOMER PERCEIVED TERHADAP LOYALITAS PELANGGAN (Suatu Studi pada Toko Rabbani Tasikmalaya)', 1, pp. 189-200. 
Dewi, S. A. (2017) 'Pengaruh Citra Perusahaan, Kepercayaan Pelanggan, Dan Kualitas Pelayanan Terhadap Loyalitas Pelanggan (Studi Kasus Pt.Buana Langgeng Jaya Tulungagung)', Jurnal Aplikasi Bisnis, pp. 244-249.

Dewi Yuliana, Heri Wijayanto, E. S. (2020) 'PENGARUH EFISIENSI, PERSEPSI RESIKO DAN TINGKAT KEMUDAHAN TERHADAP KEPUTUSAN PEMBELIAN (Konsumen Toko Online Shopee Di Ponorogo )', Manajemen dan Bisnis.

Hair, J. F. et al. (2010) 'Multivariate Data Analysis', Vectors. doi: 10.1016/j.ijpharm.2011.02.019.

Handayani, S. D. (2020) PENGARUH BRAND IMAGE, KUALITAS PELAYANAN DAN KEPERCAYAAN TERHADAP LOYALITAS NASABAH DENGAN KEPUASAN SEBAGAI VARIABEL MODERATING (Studi Kasus BRI Syariah KCP Magelang).

Harjati, L. (2020) 'PENGARUH BRAND IMAGE DAN BRAND TRUST TERHADAP LOYALITAS PELANGGAN SEPATU NIKE PADA MAHASISWA KWIK KIAN GIE SCHOOL OF BUSINESS Ezra Laurencia Institut Bisnis Dan Informatika Kwik Kian Gie Alas kaki merupakan kebutuhan mendasar bagi setiap manusia dan terdi', pp. 1-13.

Hartanto, A. and Andreani, F. (2019) 'Pengaruh Kualitas Produk, Kualitas Layanan, Dan Lingkungan Fisik Terhadap Loyalitas Pelanggan Melalui Kepuasan Pelanggan Sebagai Variabel Mediasi Di De Mandailing Cafe Surabaya', Agora, Vol 7, No(1), pp. 1-6. Available at: http://publication.petra.ac.id.

Idris, I., Sari, P. D., Ali, Y., Aisyah, S., \& Hadi, A. S. (2019, November). The Effect of taxi bike Service Quality on Customer Satisfaction among Students. In ICASI 2019: Proceedings of The 2nd International Conference On Advance And Scientific Innovation, ICASI 2019, 18 July, Banda Aceh, Indonesia (p. 1). European Alliance for Innovation.

Idris, M. (2017) Digital Digital Repository Repository Universitas Universitas Jember Jember PENGARUH RELATIONSHIP MARKETING Digital Digital Repository Repository Universitas Universitas Jember Jember.

Kottler dan Keller, (2015) 'Manajemen Pemasaran', Jilid 1, Edisi 13, Jakarta: Erlangga

Listiono, F. I. S. and Sugiarto, S. (2015) 'Pengaruh Store Atmosphere Terhadap Loyalitas Konsumen Dengan Kepuasan Konsumen Sebagai Variabel Intervening Di Liberia Eatery Surabaya', Jurnal Manajemen Pemasaran Petra.

Maya, S. et al. (2020) 'Membangun Loyalitas Pelanggan Berbasis E-Service Quality Dengan Mediasi Kepuasan Pelanggan ( Studi pada Transportasi Online Grab-Car di Kota Medan ) Building Customer Loyalty Based on E-Service Quality by Mediating Customer Satisfaction ( Study on Online', Jurnal Manajemen, Strategi Bisnis dan Kewirausahaan, 14(2), pp. 218-240.

Novia Andarwati Sitorus, R. (2020) 'PENGARUH BRAND IMAGE DAN PRODUCT QUALITY TERHADAP LOYALITAS PELANGGAN SEMEN DYNAMIX DI KOTA BATAM', Jurnal Ilmiah Kohesi, 4(3), pp. 81-89.

Nugroho, AW; Sudaryanto, B. (2013) 'Pengaruh Kinerja Layanan, Kepercayaan Dan Kepuasan Terhadap Loyalitas Konsumen Dalam Menggunakan Jasa Pengiriman Barang', Diponegoro Journal of Management, 2(3), pp. 1-9.

Oliviana, M., Lisbeth, M. and Mananeke, C. (2017) 'pengaruh brand image dan wom terhadap loyalitas konsumen', 5(2), pp. 1081-1092.

Pradana, F. (2018) 'Pengaruh Manajemen Hubungan Pelanggan, Kualitas Pelayanan, Dan Kualitas Pengalaman Terhadap Loyalitas Pelanggan Dengan Kepuasan Pelanggan Sebagai Variabel Intervening Pada Nasabah Pt Fac Sekuritas Indonesia Di Yogyakarta', Jurnal Manajemen Bisnis, 9(2), pp. 193-212. doi: 10.18196/mb.9262. 
Prasetyo, A., Ekonomi, F. and Bisnis, D. A. N. (2020) 'PERAN EXPERIENTIAL MARKETING DALAM MENDORONG CUSTOMER SATISFACTION , BRAND IMAGE DAN WORD OF MOUTH SEHINGGA MENINGKATKAN MINAT BERKUNJUNG KEMBALI NASABAH KE BANK SYARIAH ( Studi Kasus Bank BRI Syariah KCP Magelang )'.

Putra, Y. E. and Aziz, N. (2019) 'Pengaruh Kualitas Pelayanan Dan Kepuasan Pelanggan Terhadap Loyalitas Nasabah Pt Bank Rakyat Indonesia Cabang Padang', pp. 71-86. doi: 10.31219/osf.io/hcsw2.

Razak, A., Baheri, J. and Ramadhan, M. I. (2018) 'Pengaruh Kepuasan dan Kepercayaan terhadap Loyalitas Nasabah pada Bank Negara Indonesia ( BNI ) Cabang Kendari', 1(79), pp. 10-20.

Rizaldi, M. L. and Hardini, R. (2018) 'Pengaruh Kualitas Pelayanan, Brand Image Dan Customer Relationship Management Terhadap Loyalitas Pelanggan Indomaret Kelurahan Padurenan, Bekasi Timur', Jurnal Ilmu Manajemen.

Salim, A. and Zuhdi, S. (2018) 'Analisis Pengaruh Brand Image Terhadap Loyalitas Pelanggan Kopi Torabika', Jurnal Sains Manajemen dan Bisnis Indonesia, 8(2), pp. 110.

Santana, A. (2019) 'pengaruh brand image terhadap keputusan dan loyalitaspelanggan pada PT. Brand di jakarta', Journal of Chemical Information and Modeling, 53(9), pp. 16891699.

Soleh, M. (2018) 'PENGARUH KUALITAS PRODUK, KUALITAS PELAYANAN DAN KEPERCAYAAN TERHADAP LOYALITAS PELANGGAN INDOSAT OOREDOO', Jurnal Ilmu dan Riset Manajemen, 7, No 11.

Sukmawati, I. (2015) 'Pengaruh Kualitas Pelayanan Dimediasi Kepuasan Pelanggan Dan Kepercayaan Pelanggan Terhadap Loyalitas Pelanggan Pada Pt Air Manado', Jurnal Riset Ekonomi, Manajemen, Bisnis dan Akuntansi, 3(3), pp. 729-742. doi: 10.35794/emba.v3i3.9573.

Supertini, N. P. S., Telagawati, N. L. W. S. and Yulianthini, N. N. (2020) 'Pengaruh kepercayaan dan kepuasan pelanggan terhadap loyalitas pelanggan pada Pusaka Kebaya di Singaraja', Prospek: Jurnal Manajemen dan Bisnis, 2(1), p. 61. doi: 10.23887/pjmb.v2i1.26201.

Ulfa, M. and Mayliza, R. (2019) 'Pengaruh Kualitas Pelayanan Dan Kepuasan Pelanggan Terhadap Loyalitas Pelanggan Pdam Kota Padang', pp. 1-16. doi: 10.31219/osf.io/spmgv.

Utami, D. M. (2019) 'Pengaruh Program Loyalitas Terhadap Kepuasan Pelanggan ( Studi Empiris Pada Alfamart )', pp. 1-25.

Tjiptono, Fandy (2000). Perspektif Manajemen dan Pemasaran Kontemporer, Penerbit Andi Offset. 2000

Winni, A. (2020) pengaruh kualitas pelayanan dan strategi.

Wiwoho, A. S. (2018) 'PENGARUH RELATIONSHIP MARKETING, CUSTOMER VALUE, DAN TRUST TERHADAP LOYALITAS PELANGGAN PADA PT. ASURANSI JIWASRAYA CABANG KOTA MALANG', Manajemen Bisnis. doi: 10.22219/jmb.v8i2.7062. 